\title{
Intra-oral compartment pressures: a biofunctional model and experimental measurements under different conditions of posture
}

\author{
Wilfried Engelke $\cdot$ Klaus Jung $\cdot$ Michael Knösel
}

Received: 5 August 2009 / Accepted: 3 December 2009 / Published online: 2 February 2010

(C) The Author(s) 2010. This article is published with open access at Springerlink.com

\begin{abstract}
Oral posture is considered to have a major influence on the development and reoccurrence of malocclusion. A biofunctional model was tested with the null hypotheses that (1) there are no significant differences between pressures during different oral functions and (2) between pressure measurements in different oral compartments in order to substantiate various postural conditions at rest by intra-oral pressure dynamics. Atmospheric pressure monitoring was simultaneously carried out with a digital manometer in the vestibular inter-occlusal space (IOS) and at the palatal vault (sub-palatal space, SPS). Twenty subjects with normal occlusion were evaluated during the open-mouth condition (OC), gently closed lips (semi-open compartment condition, SC), with closed compartments after the generation of a negative pressure (CCN) and swallowing (SW). Pressure curve characteristics were compared between the different measurement phases (OC, SC, CCN, SW) as well as between the two compartments (IOS, SPS) using analysis of variance and Wilcoxon matched-pairs tests adopting a significance level of $\alpha=0.05$. Both null hypotheses were rejected. Average pressures (IOS, SPS) in the experimental phases
\end{abstract}

\section{W. Engelke $(\bowtie)$}

Dentistry Centre, Department of Maxillofacial Surgery, University of Göttingen,

Robert-Koch-Str. 40,

37099 Göttingen, Germany

e-mail: wengelke@med.uni-goettingen.de

K. Jung

Department of Medical Statistics, University of Göttingen,

Göttingen, Germany

M. Knösel

Dentistry Centre, Department of Orthodontics,

University Medical Centre Göttingen,

Göttingen, Germany were $0.0,-0.08(\mathrm{OC}) ;-0.16,-1.0(\mathrm{SC}) ;-48.79,-81.86$ $(\mathrm{CCN})$; and $-29.25,-62.51$ (SW)mbar. CCN plateau and peak characteristics significantly differed between the two compartments SPS and IOS. These results indicate the formation of two different intra-oral functional anatomical compartments which provide a deeper understanding of orofacial biofunctions and explain previous observations of negative intra-oral pressures at rest.

Keywords Intra-oral pressure - Biofunctional model · Functional intra-oral compartments $\cdot$ Swallowing . Oral posture

\section{Introduction}

Oral posture and equilibrium theory

The teeth and alveolus are currently believed to lie in a position of balance between the tongue, the cheek and the lips [1-4]. In the context of the aetiology of malocclusion, the influence of muscle activity and posture is usually listed under 'local factors' and little information is available about the extent of their impact or indeed how they can be assessed [4].

There is now wide agreement that muscle weakness is linked to increased vertical growth [5]. The teeth and their supporting structures are known to be highly resistant to short-term forces [3], but light forces over an extended period of time can have a dramatic effect on the skeletal bones, especially in younger children $[3,4]$.

Open-mouth posture is one of the most common disturbances of oral posture [4]. This does not exclusively refer to the mouth breathing mode [6]. As Vig et al. [7] have pointed out, open-mouth habits do not necessarily 
coincide with mouth breathing. However, open-mouth posture is necessarily associated with an open lip seal and, in turn, with a disturbance of soft tissue balance. The natural lip seal is lost in most infants in industrialised populations by the age of four [8]. Some of them develop a competent lip seal for social reasons and many continue to keep their lips apart, especially at night [4].

Patients with a high level of open-mouth posture show significantly smaller growth of the maxillary arch $[9,10]$. The influence of tongue position on malocclusion has also been confirmed by clinical and experimental research. Lundeen and Gibbs [11] and Melsen et al. [12] have noted that those who rest and swallow with their teeth in contact have less malocclusion, suggesting that postures with the tongue between teeth could also cause malocclusion. Harvold et al. [13] experimentally displaced the tongues of monkeys from the normal position and observed widespread occlusal and skeletal consequences, with considerable reduction of the maxillary arch width in every juvenile animal. This suggests that changes in muscle posture have a greater influence than muscle function [4].

Orofacial dysfunction is believed to depend on neuromuscular activity. In 1873, Tomes [14] drew attention to the fact that 'along the outside of the dental arch the muscular structures of the lips and cheeks are perpetually exercising pressure perfectly symmetrically, and on the inside, the tongue is with equal persistence doing the same thing'. The muscular equilibrium was described by Tomes [14] and later cited by various authors $[15,16]$, although pressure measurements provided evidence that tongue pressure during swallowing exceeds that of labial pressure [17-19]. Proffit [3] therefore assumed additional factors must be acting in the equilibrium of forces. Recently, Ruan et al. [20] reiterated previous assumptions that dentition is in a state of balance between forces from the outside, i.e. the lips and cheeks, and forces from the inside, i.e. the tongue. The model underlying this equilibrium theory is based on the assumption that active neuromuscular forces are responsible for the equilibrium of tooth position (Fig. 1).

\section{Biomechanical conditions of oral posture}

Amongst many other factors, oral posture is dependent not only on muscular forces but also on biomechanical conditions, including the formation of secluded oral functional compartments which, in the past, has received little attention in the literature. Therefore, we need to outline some basic conditions of oral posture.

Intra-oral functional compartments have been mentioned in the literature for more than 50 years. In 1953, EckertMöbius [21], based on the publication of Noltemeier [22]

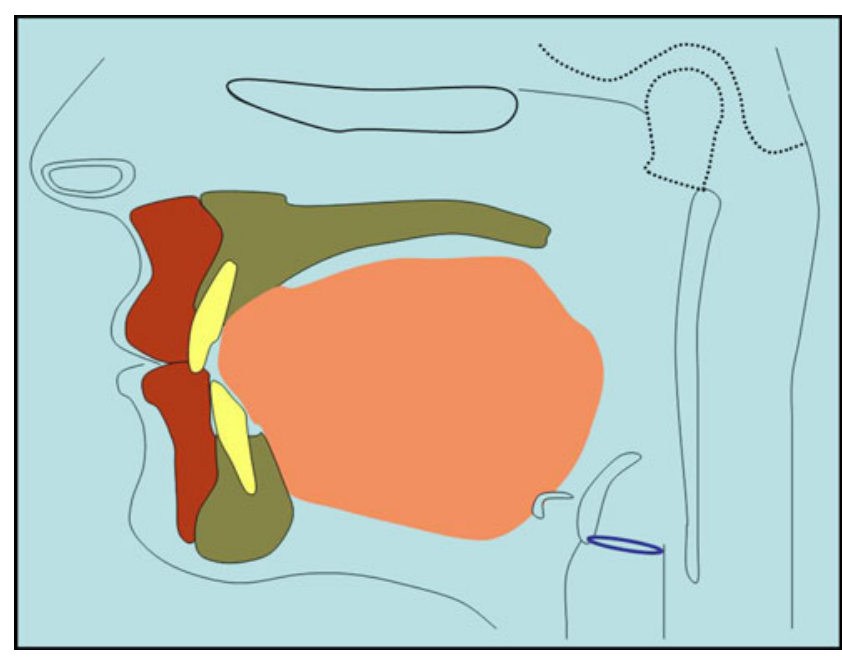

Fig. 1 Conventional functional model of soft tissue function (see Proffit [32]): lip and tongue postures influence the position of the teeth

and proposals of Körbitz published in 1914 [23], described two different functional 'suction spaces', one of them around the dental arches (the later inter-occlusal space of Fränkel [24]) and the other below the palatal vault. The formation of a negative pressure at the palatal vault was later confirmed by Fröhlich et al. [25]. Engelke [26] systematically depicted orofacial biofunctional compartments as part of a comprehensive biofunctional model. Biofunctional compartments are spaces formed during particular biological functions, such as deglutition, speech production and respiratory posture: inter-occlusal space (IOS), sub-palatal space (SPS), mid-pharyngeal space and the naso-epipharyngeal space (Fig. 2).

The biomechanics of the orofacial system can be described in detail based on the biofunctional compartment model.

Open condition (OC) is synonymous with an openmouth posture. In the case of a visibly open lip seal, intraoral compartments, i.e. intraoral spaces, communicate with the environment at atmospheric pressure. The posture of oral structures in the OC condition mainly depends on muscle tone and gravity $[15,21,24]$. Spontaneous mobility of oral structures within the full range of anatomical conditions is possible and can be directly observed, but no certain prediction of tongue and jaw posture can be made (Fig. 3a).

\section{Semi-open condition}

The oral cavity is a partially closed compartment with the lips closed. No unequivocal statement can be made about posterior mouth closure or tongue position. Therefore, communication via an incomplete posterior seal to the mesopharyngeal airway may provide an open condition for oral compartments (Fig. 3b). 


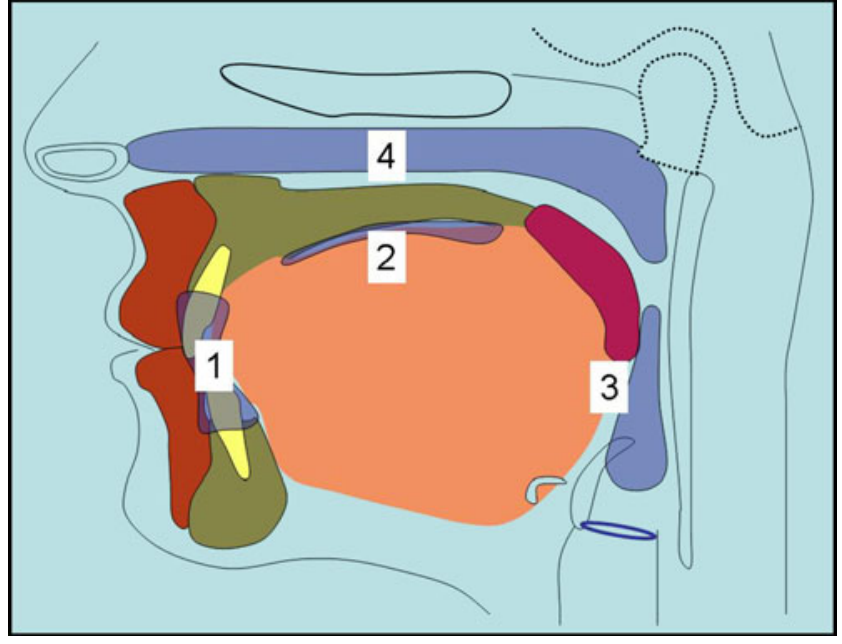

Fig. 2 Biofunctional compartment model of the orofacial system (see Engelke [10]): closure of the lips and placement of the tongue at the hard palate form the inter-occlusal compartment (IOS, 1). Contacting of posterior tongue and soft palate supports closure of the sub-palatal compartment (SPS, 2), whereas the tongue and hard palate contact area separates both compartments 1 and 2. The upper airway in conjunction with the velopharyngeal sphincter as borderline forms two further biofunctional compartments (3 and 4)

\section{Closed condition}

The closed condition (CC) is different from the semi-open condition (SC) and represents a state of pressure-resistant closure of the oral cavity. Clinically, CC can be verified using certain manoeuvres to generate positive or negative intra-oral pressures: The cheek-blowing manoeuvre is an example of the closed condition with positive intra-oral pressure (CCP). The lip seal and posterior mouth closure are actively supported by muscle contraction, and the tongue is mobile. The tongue repositioning manoeuvre (Engelke [39]) is an example of the closed condition with negative intra-oral pressure $(\mathrm{CCN})$ and was first referred to by Körbitz [23]. The tongue is stabilised in a palatal position (Fig. 4).

There are important biomechanical differences between the $\mathrm{CCP}$ and $\mathrm{CCN}$ conditions. $\mathrm{CCP}$ is an active manoeuvre. $\mathrm{CCN}$ is a posture which does not require continuous, active mouth closure. CCP allows voluntary movement of intra-oral structures within given anatomical limits. For anatomical reasons, an externally directed check-valve function of the lips and the velolingual seal is not present. Therefore, CCP always requires continuous neuromuscular activity and, in turn, is merely an active oral manoeuvre rather than an oral resting posture. $\mathrm{CCN}$ requires the generation of sub-atmospheric, intraoral pressure using an oral pump function which is performed during the act of swallowing. $\mathrm{CCN}$ is associated with a reduction in intra-oral fluid (gas) volumes ('evacuation') before closure of the oral valves (Fig. 5). The resulting internally directed pressure gradient between the environment and the oral biofunctional compartments acts as a compressive force on the elastic oral walls and thus impedes an expansion of the closed oral compartment volume. $\mathrm{CCN}$ results in restricted movement and stabilised posture of the tongue and the oral walls.

\section{Swallowing}

Swallowing (SW) is one prerequisite for achieving the $\mathrm{CCN}$ condition [23]. Electromagnetic motor analysis of tongue and velar surface coordination has revealed that the oral phase is characterised by the formation of an anterior seal between the tongue and the palate while maintaining linguovelar closure [27], which is compatible with the formation of two separate compartments. The elevation of

a

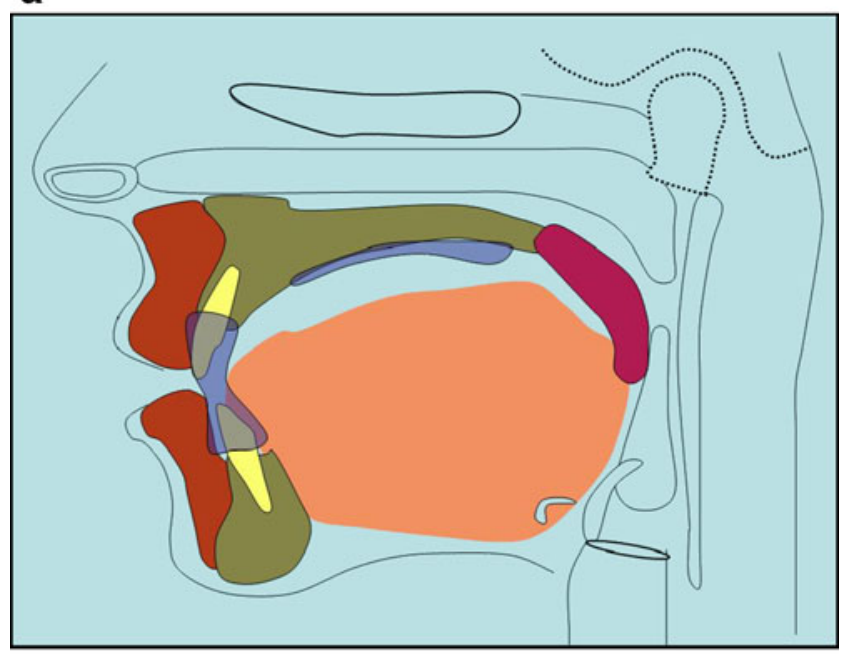

b

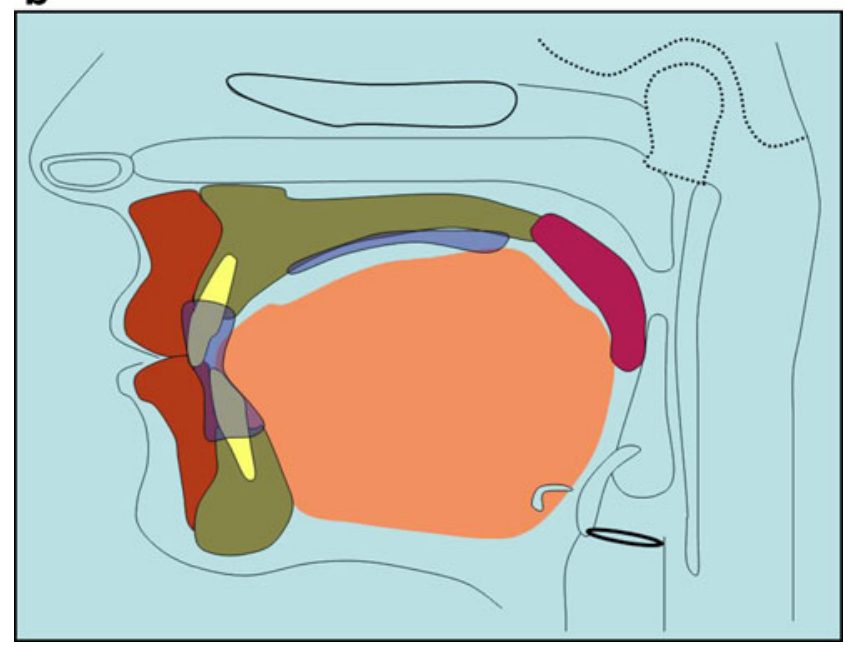

Fig. 3 a Open condition (OC): free tongue movement possible, neuromuscular determination of jaw and tongue position, no closure of compartments possible. b Semi-open condition (SC): neuromuscular determination of jaw and tongue position. Lip closure visible, posterior mouth closure status not determined 


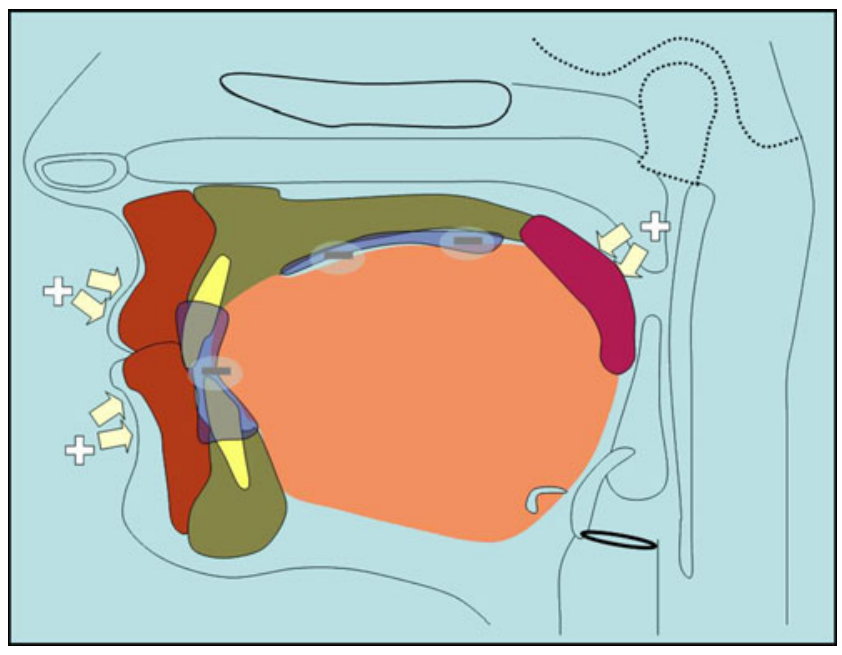

Fig. 4 Closed condition negative pressure $(\mathrm{CCN})$ following tongue repositioning manoeuvre: atmospheric pressure supports closure of the compartments

the soft palate and contraction of the velopharyngeal sphincter are part of the subsequent pharyngeal phase. Figure 5 shows the commencement of velopharyngeal contraction with both an anterior tongue seal and posterior velolingual contact. Recent research [28, 29] has also provided evidence that a negative pressure wave can be observed in the oral phase of swallow.

The aim of the present study was to evaluate pressure dynamics in the oral biofunctional compartments at rest, in normal subjects, under different conditions of postural and, in turn, different biomechanical conditions. The intention was to monitor compartment pressure curves during rest under open, semi-open and closed negative pressure conditions compared with the act of swallowing.

The null hypotheses were that (1) there are no significant differences in pressure curve characteristics between the

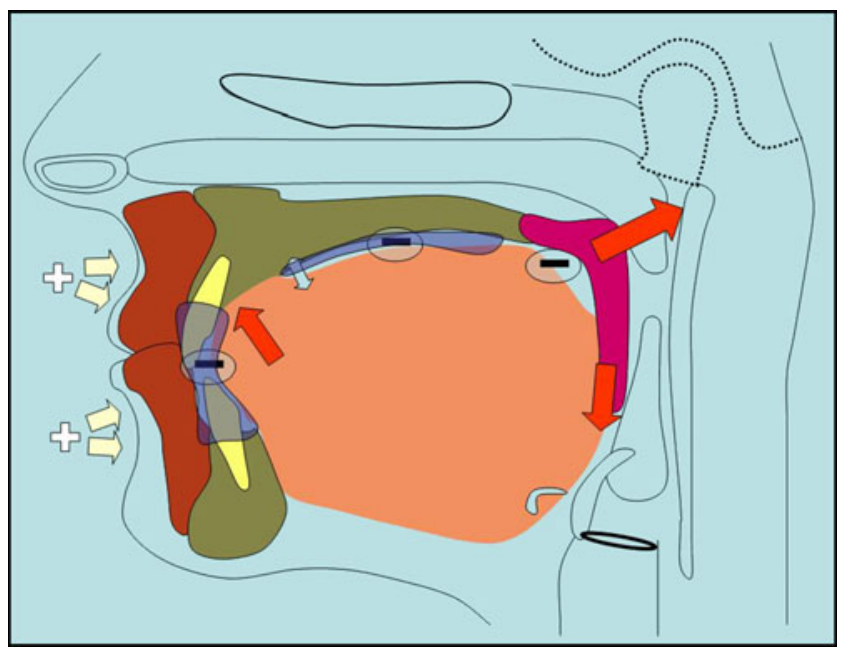

Fig. 5 Deglutition, start of velopharyngeal activity with negative intra-oral pressure formation different functional phases (OC, SC, CCN, SW) and (2) between the measurements in the different oral compartments, the IOS and the SPS formed between the palatal vault and the tongue surface.

\section{Subjects}

Twenty Caucasian subjects (nine males and 11 females; mean age 28.05 years; SD 8.34) were randomly selected according to the following inclusion criteria: normal occlusal sagittal, vertical and transverse relationships, as characterised by Angle Class I molar and cuspid relations, absence of cross-bites and well-set interincisal relations without major crowding. Obstructed airways (anamnestic evaluation) and clinically disturbed nasal respiration at rest defined the exclusion criteria. All participants were 18 years of age or older and gave informed consent for taking part in the study. The study received the approval of the local ethics committee.

\section{Methods}

Intra-oral pressure monitoring with a handheld digital precision measuring instrument was carried out on each participant using two different oral end fittings: a polyethylene semi-flexible intravenous catheter (Braun, Melsungen, Germany) and a standardised, air-permeable dental suction end cap. Both were fitted to a flexible PVC tube (4 $\mathrm{mm}$ inside diameter) and connected to a piezoresistant relative pressure sensor (GMSD 350 MR; Greisinger electronic $\mathrm{GmbH}$, Regenstauf, Germany) able to record pressures with a measuring range of $500 \mathrm{mbar}$ (rel.) $(+100$ to -400 mbar) and a resolution of $0.1 \mathrm{mbar}$ relative pressure. Measurement of atmospheric pressure was performed at two intra-oral sites with open-ended catheters: in the vestibular aspect of the IOS and at the sub-palatal space between the palatal vault and the tongue surface (SPS). In order to obtain a continuous communication to the inter-occlusal space and, at the same time, to avoid obstruction of the sensor tip by the buccal mucosa, the dental suction end cap was placed in the buccal vestibulum lateral to the bicuspid region. In order to measure the palatal vault, the venous catheter was placed through an inter-dental space in the anterior teeth with the tip ending at the centre of the palatal vault in order to reduce interference with the tongue dorsum to a minimum. All measurements were carried out chairside, by one assessor, in the Department of Orthodontics at the University of Göttingen. The study setup is depicted in Fig. 6a. Subjects were seated in a comfortable, upright position in a dental chair and were asked to follow 
Fig. 6 a Study setup: manometric measurements were performed chair-side at the sub-palatal space (SPS) and at the inter-occlusal space (IOS). b Subject during measurement

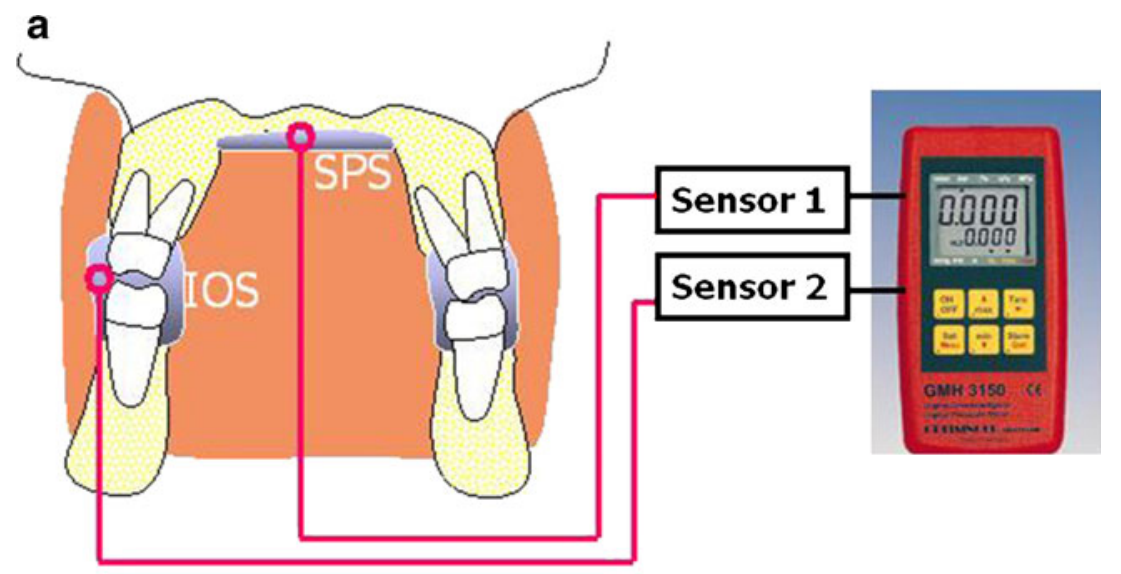

b

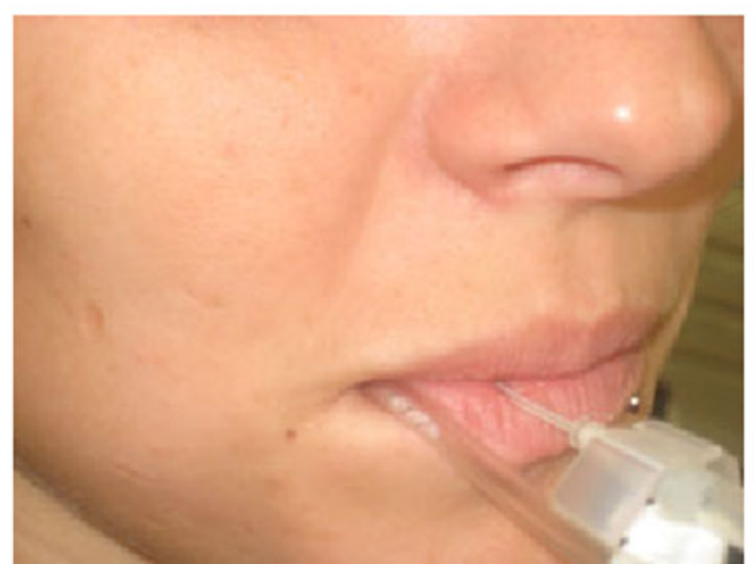

the instructions of the examiner (Fig. 6b). The experiment was performed in four phases:

Phase 1,0-30 s: Subjects were asked to open the lips slightly and to breathe quietly. Pressure monitoring was performed under the open-mouth condition (OC). Phase 2, 30-90 s: Subjects were asked to close their lips gently and to continue breathing quietly. The semiopen condition (SC) was recorded for $60 \mathrm{~s}$.

Phase 3, 90-150 s: Subjects were asked to collect saliva, swallow the saliva collected and subsequently to breathe quietly for $60 \mathrm{~s}$. A closed-compartment, negative pressure condition $(\mathrm{CCN})$ was recorded.

Phase 4, 150-165 s: Subjects were asked to swallow their saliva.

For further data evaluation, the following time intervals were selected. Transient phases between the different conditions were eliminated from the evaluation:

Phase 1 (OC): 0-25 s.

Phase 2 (SC): $35-85 \mathrm{~s}$.

Phase 3 (CCN): 95-145 s.

Phase 4 (SW): 150-165 s.
The data of four experimental phases were processed using the Windows operating software GSOFT 3050 (Greisinger electronic $\mathrm{GmbH}$ ). In the analysis of data, plateau phases and pressure peaks were differentiated and average pressures under the curve calculated. Plateaus included a pressure oscillation of less than $5 \mathrm{mbar} / \mathrm{s}$ and duration of at least $5 \mathrm{~s}$ in order to distinguish plateau phases from the duration of normal swallowing [28]. Peaks were defined as a change in pressure of at least $5 \mathrm{mbar} / \mathrm{s}$ within $2 \mathrm{~s}$ and a second change (decrease) of at least $5 \mathrm{mbar} / \mathrm{s}$ within $5 \mathrm{~s}$ after the start of the change. The frequencies of peaks and plateau stages and the duration and magnitude of the plateau stages were evaluated.

\section{Statistical methods}

The characteristics derived from the pressure curves (i.e. peak and plateau frequencies, average peak and plateau height, average pressure) were compared between the different measurement phases (OC, SC, CCN and swallow) as well as between the inter-occlusal and palatal vault compartments by a non-parametric, two-way analysis of variance (ANOVA) for repeated measures [30]. Subsequent Wilcoxon matched-pairs 
tests were performed to separately compare the inter-occlusal and palatal vault measurement at each phase.

Figures and descriptive analyses were produced in R (V 2.6, www.r-project.org). ANOVA was carried out with SAS 9.1 (SAS Institute, Cary, NC, USA). The significance level was set to $\alpha=5 \%$ for all tests.

\section{Results}

Error analysis

To determine intra-individual variation of pressure characteristics, measurements of two subjects with eight repetitions of each run were carried out (see Table 1). Peak and plateau frequencies differed only slightly between the measurement repetitions. The highest individual variation was observed for the average peak height during $\mathrm{CCN}$ (inter-quartile range $84.8 \mathrm{mbar}$ ). For the peak and plateau frequencies, variations did not exceed a value of 2 .

\section{Experiment}

ANOVA revealed a significant phase effect for all curve characteristics (all $p<0.01$, Table 2 ), and the null hypothesis (1) was rejected. An example of a measurement is shown Fig. 7. In the open compartment (OC) phase, atmospheric pressure with small negative phases in the IOS compart-
Table 2 Significance of the effects of measuring point and measuring phases on the different curve characteristics as indicated by $p$ values

\begin{tabular}{lccc}
\hline Parameter & $\begin{array}{l}\text { Measuring point } \\
\text { effect }\end{array}$ & Phase & Interaction \\
\hline Peak frequency & 0.04 & $<0.01$ & 0.01 \\
Plateau frequency & 0.03 & $<0.01$ & 0.03 \\
Average peak height & 0.03 & $<0.01$ & $<0.01$ \\
Average plateau height & $<0.01$ & $<0.01$ & 0.17 \\
Average pressure & $<0.01$ & $<0.01$ & 0.32 \\
\hline
\end{tabular}

ment is shown. SC phase shows a nearly identical pressure profile. In the $\mathrm{CCN}$ phase, the IOS pressure was stable at a plateau, while the palatal vault pressure shows activity peaks at negative pressure levels below -20 mbar. One swallowing peak is detectable at -70 mbar height.

Using ANOVA, an overall measurement site effect was detected for all curve parameters (Table 2) so that the null hypothesis (2) could also be rejected. Significant interactions between measurement site, i.e. the oral compartments measured, and experimental phase were detected for peak and plateau frequency $(p=0.01112, p=0.03228)$ as well as for average peak height $(p=0.00053)$. These interactions mean that the magnitude of the difference between IOS and SPS measurements is different for particular experimental phases. The subsequent Wilcoxon tests revealed that the difference between IOS and SPS measurements is signifi-

Table 1 Inter-quartile ranges of eight repeated measurements on two subjects at IOS and SPS for different curve parameters during different experimental phases

\begin{tabular}{|c|c|c|c|c|c|c|c|}
\hline \multirow{2}{*}{$\begin{array}{l}\text { Measurement } \\
\text { point }\end{array}$} & \multirow[t]{2}{*}{ Subject } & \multirow[t]{2}{*}{ Phase } & \multicolumn{5}{|c|}{ Inter-quartile range } \\
\hline & & & $\begin{array}{l}\text { Peak } \\
\text { frequency }\end{array}$ & $\begin{array}{l}\text { Plateau } \\
\text { frequency }\end{array}$ & $\begin{array}{l}\text { Average peak } \\
\text { height }\end{array}$ & $\begin{array}{l}\text { Average plateau } \\
\text { height }\end{array}$ & $\begin{array}{l}\text { Average } \\
\text { pressure }\end{array}$ \\
\hline \multirow[t]{8}{*}{ IOS } & \multirow[t]{4}{*}{1} & $\mathrm{OC}$ & 0.0 & 0.0 & 0.0 & -0.3 & -0.4 \\
\hline & & $\mathrm{SC}$ & 0.0 & 0.0 & 0.0 & -1.0 & -1.0 \\
\hline & & $\mathrm{CCN}$ & 0.2 & 0.0 & -15.0 & -25.6 & -28.1 \\
\hline & & SW & 1.0 & 0.0 & -56.0 & -45.7 & -30.7 \\
\hline & \multirow[t]{4}{*}{2} & $\mathrm{OC}$ & 0.0 & 0.2 & 0.0 & -0.1 & -0.3 \\
\hline & & $\mathrm{SC}$ & 0.0 & 0.0 & 0.0 & -1.3 & -1.3 \\
\hline & & $\mathrm{CCN}$ & 0.0 & 0.2 & 0.0 & -15.7 & -15.7 \\
\hline & & SW & 0.0 & 1.0 & 0.0 & 0.0 & -17.6 \\
\hline \multirow[t]{8}{*}{ SPS } & \multirow[t]{4}{*}{1} & $\mathrm{OC}$ & 0.0 & 0.0 & 0.0 & -0.4 & -0.5 \\
\hline & & $\mathrm{SC}$ & 0.0 & 0.0 & 0.0 & -1.9 & -1.5 \\
\hline & & $\mathrm{CCN}$ & 1.0 & 0.0 & -67.0 & -25.7 & -26.5 \\
\hline & & SW & 0.2 & 1.0 & -20.0 & -11.4 & -30.5 \\
\hline & \multirow[t]{4}{*}{2} & $\mathrm{OC}$ & 0.0 & 0.2 & 0.0 & -1.1 & -0.9 \\
\hline & & $\mathrm{SC}$ & 0.0 & 0.0 & 0.0 & -1.8 & -1.8 \\
\hline & & $\mathrm{CCN}$ & 1.0 & 0.0 & -84.8 & -28.8 & -29.7 \\
\hline & & SW & 0.0 & 1.0 & 0.0 & 0.0 & -18.4 \\
\hline
\end{tabular}


Fig. 7 Pressure/time diagram during the experiment: brown curve sub-palatal space (SPS), blue curve inter-occlusal space (IOS)

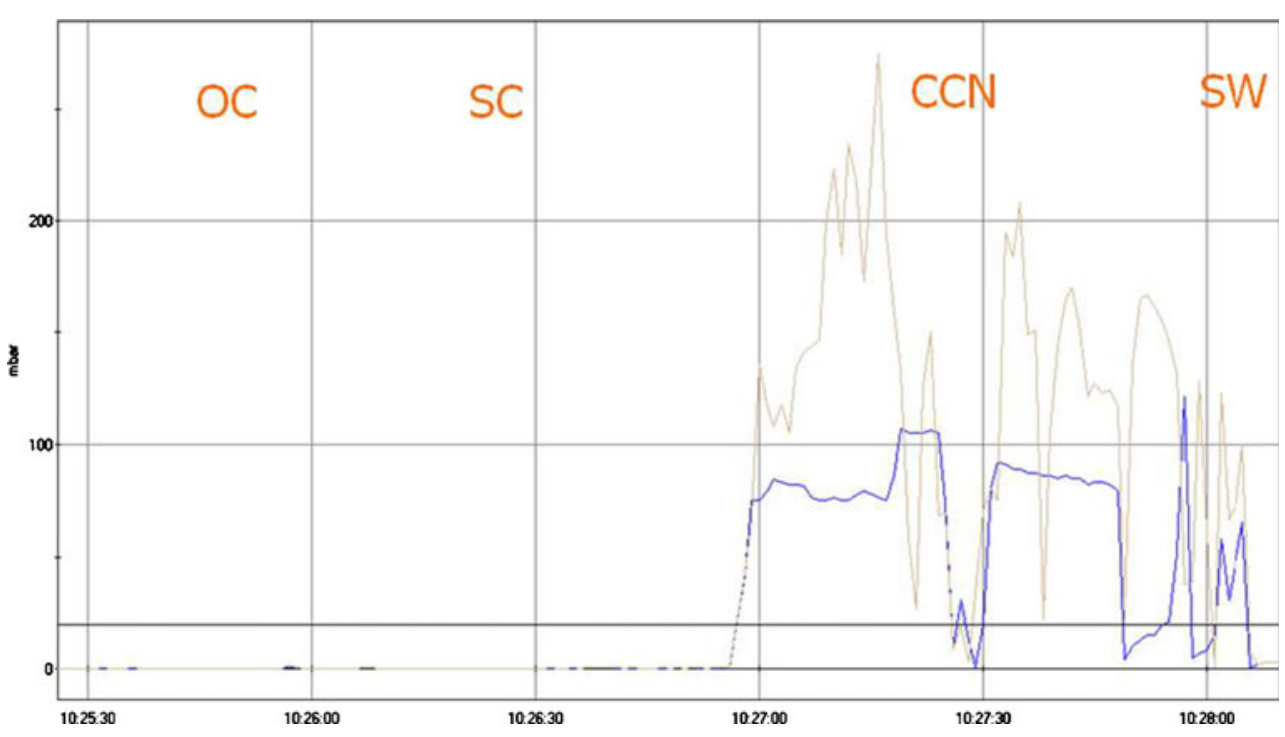

cant in the CCN phase for all curve characteristics and also in the swallowing phase in terms of the average peak height and average pressure (Table 3).

Negative pressures ranging between -50 and -150 mbar were detected in the $\mathrm{CCN}$ phase and during swallowing (Figs. 8 and 9). A marked difference in average pressure parameters was observed between the OC and SC condition on one hand and the $\mathrm{CCN}$ and swallowing phases on the other.

Analysis of average peak numbers showed that, during OC and SC, no peaks and plateaus were formed, indicating a rest position without active compartment formation. However, during the CCN phase, there was a higher peak number in SPS measurements which indicated a different behaviour of IOS and SPS curve characteristics. Similarly, the plateau frequency in the SPS exceeded the plateau frequency measured in the IOS. In the swallowing phase, one average peak and plateau was observed.

No spontaneous positive pressure peaks or plateaus were observed during the experiment.

Average peak heights in SPS are generally negative and exceed the average peak height in IOS; plateau height generally corresponds to peak height, i.e. plateau formation is present in $\mathrm{CCN}$ and SW conditions.

The distribution of average pressures (Fig. 10) shows that $\mathrm{OC}$ and $\mathrm{SC}$ on one hand and $\mathrm{CCN}$ and SW on the other represent similar biomechanical conditions; $\mathrm{CCN}$ and $\mathrm{SW}$ phase conditions show different compartment-dependent pressures.

\section{Discussion}

Experimental postural conditions and pressure dynamics

Our data show that, under the OC condition, no significant pressure difference from atmospheric pressure could be observed, indicating that spontaneous compartment formation does not occur. OC conditions, therefore, can be used as a baseline pressure measurement for different postural conditions.

Under SC condition, the average pressure in the SPS compartment showed negative values $(1 \mathrm{mbar})$ and therefore appear compatible with a temporary formation of a closed compartment. The IOS average pressure $(0.16 \mathrm{mbar})$, however, did not significantly differ from the pressure under the OC condition. Comparing the variations observed intra-individually with the sizes of the detected effects by experimental phase and measurement site, it may be that the variations overlay the effects.

$\mathrm{CCN}$ condition represents the posture achieved by the tongue repositioning manoeuvre, i.e. swallowing saliva with subsequent nasal respiration. Pressure data under this experimental condition showed large- scale negative pressure values with considerable variation. In SPS, an average negative pressure of -81.86 mbar was observed, whereas in the IOS, -48.79 mbar was measured. Comparing pressure dynamics in the IOS and SPS, the peak and plateau frequency in SPS was higher, indicating activity of the wall structures of SPS soft palate and tongue. The IOS maintains its posture with less measurable activity at smaller pressure plateaus. Activity patterns show that the generation of negative pressure is achieved by the wall structure of the SPS, whereas the IOS mainly plays a passive role. However, it remains unclear whether there is an influence of the measuring system, as a result of a loss of pressure, which may provoke repetitive activity of the SPS walls. Moreover, the data indicate that the two compartments partly act as independent units.

Swallowing condition recorded at the fourth phase of the experiment represents a repetition of the $\mathrm{CCN}$ phase without subsequent maintenance of negative pressure. It, therefore, could be expected that pressure levels have a similar magnitude. The dynamics show one average peak 
Table 3 Comparisons of curve characteristics between IOS and SPS measurements in the different experimental phases

\begin{tabular}{|c|c|c|c|c|c|c|}
\hline Parameter & Phase & Measuring point & $25 \%$ quartile & $50 \%$ quartile & $75 \%$ quartile & $p$ value (Wilcoxon) \\
\hline \multirow[t]{8}{*}{ Peak frequency } & $\mathrm{OC}$ & IOS & 0.00 & 0.00 & 0.00 & - \\
\hline & & SPS & 0.00 & 0.00 & 0.00 & \\
\hline & $\mathrm{SC}$ & IOS & 0.00 & 0.00 & 0.00 & 1.00 \\
\hline & & SPS & 0.00 & 0.00 & 0.00 & \\
\hline & $\mathrm{CCN}$ & IOS & 0.00 & 1.00 & 2.00 & $<0.01$ \\
\hline & & SPS & 1.00 & 4.00 & 5.00 & \\
\hline & SW & IOS & 0.00 & 0.00 & 1.00 & 0.07 \\
\hline & & SPS & 0.00 & 1.00 & 1.00 & \\
\hline \multirow[t]{8}{*}{ Plateau frequency } & $\mathrm{OC}$ & IOS & 1.00 & 1.00 & 1.00 & 0.35 \\
\hline & & SPS & 1.00 & 1.00 & 1.00 & \\
\hline & $\mathrm{SC}$ & IOS & 1.00 & 1.00 & 1.00 & 0.35 \\
\hline & & SPS & 1.00 & 1.00 & 1.00 & \\
\hline & $\mathrm{CCN}$ & IOS & 1.00 & 1.00 & 2.25 & $<0.01$ \\
\hline & & SPS & 2.00 & 5.50 & 8.00 & \\
\hline & SW & IOS & 1.00 & 2.00 & 2.00 & 0.34 \\
\hline & & SPS & 1.00 & 1.00 & 2.00 & \\
\hline \multirow[t]{8}{*}{ Average peak height } & $\mathrm{OC}$ & IOS & 0.00 & 0.00 & 0.00 & - \\
\hline & & SPS & 0.00 & 0.00 & 0.00 & \\
\hline & $\mathrm{SC}$ & IOS & 0.00 & 0.00 & 0.00 & 0.18 \\
\hline & & SPS & 0.00 & 0.00 & 0.00 & \\
\hline & $\mathrm{CCN}$ & IOS & 0.00 & -28.50 & -53.67 & $<0.01$ \\
\hline & & SPS & -72.56 & -95.27 & -157.6 & \\
\hline & SW & IOS & 0.00 & 0.00 & -87.75 & 0.03 \\
\hline & & SPS & 0.00 & 75.50 & -113.20 & \\
\hline \multirow[t]{8}{*}{ Average plateau height } & $\mathrm{OC}$ & IOS & 0.00 & 0.00 & 0.00 & $<0.01$ \\
\hline & & SPS & 0.00 & -0.09 & -0.45 & \\
\hline & $\mathrm{SC}$ & IOS & -0.02 & -0.16 & -1.30 & 0.25 \\
\hline & & SPS & -0.11 & -0.92 & -1.80 & \\
\hline & $\mathrm{CCN}$ & IOS & -29.52 & -44.89 & -61.71 & $<0.01$ \\
\hline & & SPS & -61.08 & -77.92 & -138.20 & \\
\hline & SW & IOS & -17.57 & -43.08 & -59.62 & 0.06 \\
\hline & & SPS & -21.76 & -76.51 & -130.40 & \\
\hline \multirow[t]{8}{*}{ Average pressure } & $\mathrm{OC}$ & IOS & 0.00 & 0.00 & 0.00 & $<0.01$ \\
\hline & & SPS & 0.00 & -0.08 & -0.49 & \\
\hline & $\mathrm{SC}$ & IOS & -0.01 & -0.16 & -2.45 & 0.28 \\
\hline & & SPS & -0.11 & -1.00 & -2.87 & \\
\hline & $\mathrm{CCN}$ & IOS & -28.45 & -48.79 & -60.38 & $<0.01$ \\
\hline & & SPS & -57.87 & -81.86 & -140.70 & \\
\hline & SW & IOS & -22.80 & -29.25 & -48.13 & 0.02 \\
\hline & & SPS & -37.35 & -62.51 & -95.58 & \\
\hline
\end{tabular}

formation in the SPS and no peak in the IOS. The average negative pressure in SPS $(-62.52$ mbar) exceeds the average pressure in the IOS $(-29.25 \mathrm{mbar})$, as observed during $\mathrm{CCN}$. Again, one average independent pressure peak formation was shown in the SPS, indicating the presence of two separately acting functional units.

\section{Magnitude of intra-oral pressure measurements}

One of the most striking results of our study was the absence of positive pressure values during all conditions measured. Previous tests of the measuring system revealed that a technical error could be excluded. Additional observations in patients with pathological motor activity of the tongue after tumour resection revealed that occasionally positive pressure waves in the compartments can be observed in pathological conditions. This observation is basically contradictory to the findings of many authors who observed positive pressures during chewing, during swallowing and at rest [17, 19, 31, 32]. Thüer et al. [33] also reported positive pressures between soft tissues and teeth at rest. However, the authors observed that approximately half 

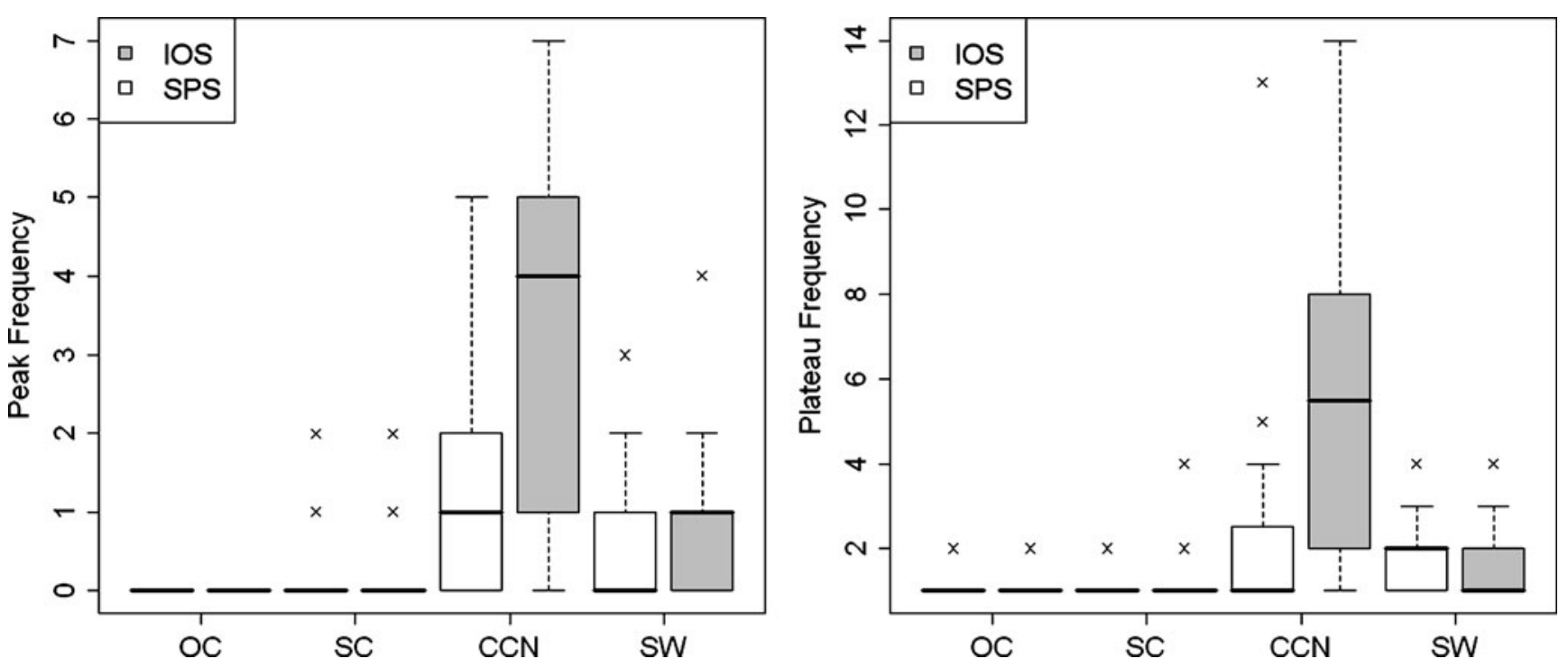

Fig. 8 Distribution of number of peaks (left) and number of plateaus (right) in the different measurement phases at palatine and cheek

of the subjects had a negative pressure at the palatal vault. Walpole Day and Foster [34] have already reported that negative pressures measured at the palatal vault should be sealed by the tongue from the rest of the cavity but, in the case of a low tongue position, would also be measurable in the buccal fold. The latter proposal supports the biofunctional compartment model presented here, with the tongue acting temporarily like a valve mechanism between SPS and IOS.

According to the model, orofacial soft tissues may act as elastic walls of functional compartments. Any closed compartment with elastic walls and an inwardly directed pressure gradient may cause positive pressure on rigid structures in its lumen, according to the principle of an elastic vacuum chamber. Therefore, negative pressure

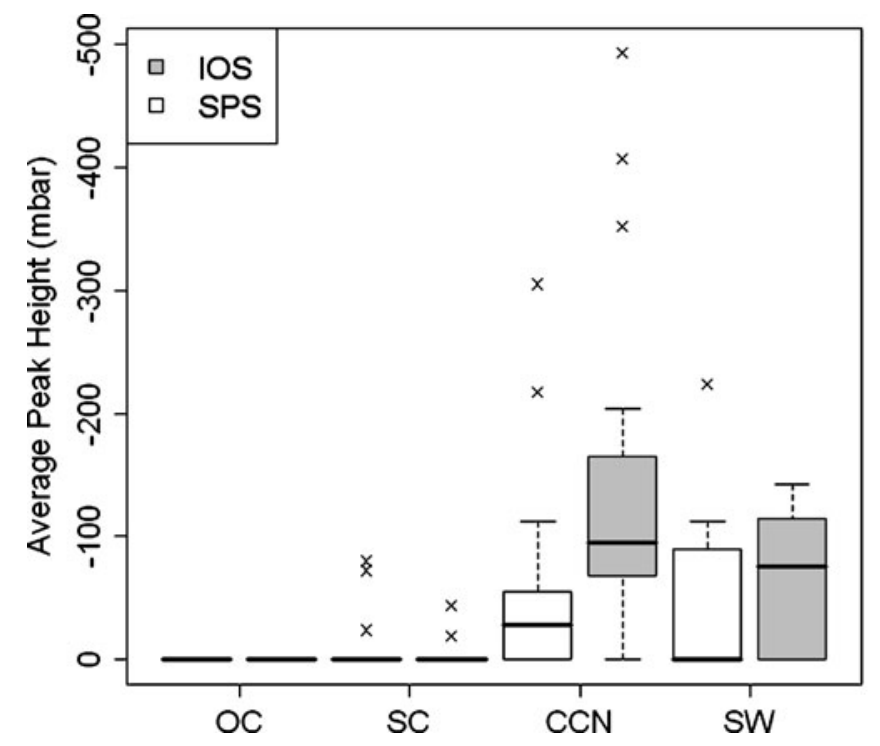

inside the functional compartments and positive pressures between soft tissues and teeth or palate may simultaneously coexist. They may additionally act in variable combination with the neuromuscular activity of the walls in the valve areas at the border between the compartments. Consequently, the biofunctional model explains negative as well as positive forces on the hard tissues within normal biological functions.

Compartment pressure and valve area during and after swallowing

The negative pressures measured in the SPS compartment as well as in the IOS are in line with recent findings of Kieser et al. [28] who stated that 'The most important of

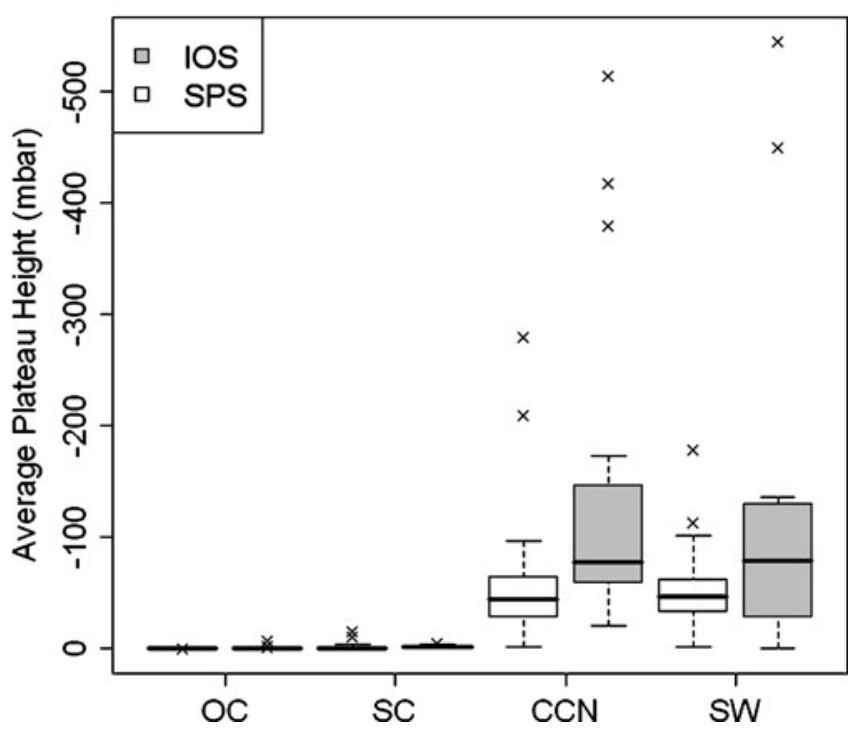

Fig. 9 Distribution of average peaks height (left) and average plateau height (right) in the different measurement phases at the SPS and IOS 


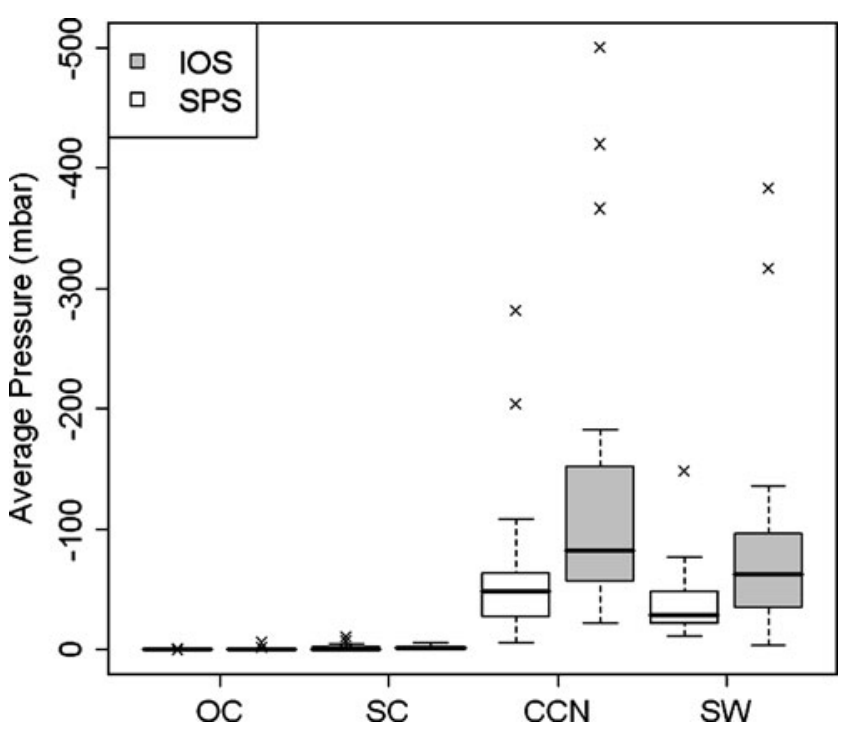

Fig. 10 Distribution of average pressure in the different measurement phases in IOS and SPS

these (findings) would be the observation of negative pressure in the mouth during swallowing'. In general, observation of negative intra-oral pressure is supported by studies of Shellhardt et al. [35], Thüer et al. [33] and Ruan et al. [20], but previous explanations remained unresolved. Kieser et al. [28] emphasised the large-scale negative pressure during swallowing in their study. They also mentioned both positive and negative pressures generated by the orchestrated movements of the tongue during swallowing.

Ono et al. [36] stated that '...pressures towards the back of the mouth actually fall rapidly before a wave of increased pressure propels the bolus towards the back of the palate'. The description of Ono et al. [36] as well as the data of Kieser et al. [28] is compatible with the assumption of a functional SPS compartment which is first evacuated by the action of the velopharyngeal complex and simultaneous persistence of a linguopalatal seal with separation of the IOS and SPS. According to the biofunctional model, valve areas should show positive pressure peaks, while the atmospheric pressure inside the compartment remains at a large-scale negative level. With the changing contact area of the tongue and the palate, a proceeding area of positive pressure may be measured (a combination of active valve tongue pressure and negative compartment atmospheric pressure). The proceeding tongue action towards the posterior palatal region can be observed by electromagnetic articulography [27, 37] but, in the light of pressure measurement, it might not be interpreted as active propulsion of the bolus, but simply the formation of a peripheral seal.

Negative pressure at rest, as observed by Fröhlich et al. [25], may be explained in view of our data as a postdeglutition, closed $(\mathrm{CCN})$ rest position. Our study shows that, after performing the tongue repositioning manoeuvres, plateaus of negative pressure can be observed in the IOS and the SPS. This confirms the self-observations of Körbitz [23] who described a comfortable rest position after forced swallowing with strong tongue palate contact. Biomechanical closure of the compartments is a status of stabilised soft tissues and equilibrium of forces, which can be observed in both the IOS and the SPS compartments. The negative pressure condition in the compartment provides mechanical stability and acts as a closing force, instead of neuromuscular activity to place the tongue in a superior palatal contact position, according to the principle of elastic vacuum chambers and, additionally, by cohesive fluid surface forces. In the valve area, there may be additional muscle contraction to support the separation of IOS and SPS.

\section{Clinical aspects}

The basic idea behind the development of the biofunctional model was that different functional compartments are formed which, in a closed status with sub-atmospheric pressure, may serve as biomechanical stabilising factors going beyond the pure neuromuscular activity of orofacial structures. Since Tomes [14], the majority of theoretical concepts of orofacial equilibrium have been focused on an isolated observation of the tongue and lip/cheek function, without special regard to the posterior closure mechanism of the orofacial system [3]. Lip and tongue function are mainly regarded to be 'myofunctional' phenomena. The results of our study, in conjunction with the biofunctional model, allow us to conclude that an isolated observation of functional elements such as the tongue may result in erroneous results if the posterior functional valve complex is disregarded, but which plays an important role in oral posture during and after swallowing and enables a subject to voluntarily generate a $\mathrm{CCN}$ condition which, in turn, may serve as a therapeutic rest position. Negative pressures during deglutition thus may be 'maintained' in the IOS and SPS over larger periods, thereby offering a biomechanical equilibrium of forces between external and internal aspects of the IOS surrounding the dental arches. Under this condition, the tongue at the palate does not act as unidirectional dislocating force but as part of the pump mechanism leading to $\mathrm{CCN}$ system conditions.

A second clinical aspect is given with regard to compartment closure during sleep. It has been shown that predominantly mechanical rather than neuromuscular factors modulate the properties of the pharynx after abrupt reductions in nasal pressure [38]. Therefore, upper airway resistance during sleep may be decreased during nasal breathing with closed oral compartments than during oral breathing and open compartments, which mostly coincides 
with a tendency for posterior displacement of the tongue. Accordingly, preliminary radiographic findings $[39,40]$ and recent clinical results [41] in the treatment of snoring can be interpreted that closure of intra-oral compartments reduces the formation of obstructions in the mid-pharyngeal compartment as part of the upper airway.

The detection of malocclusion-related intra-oral pressure levels could provide a basis for the development of treatment approaches to achieve a permanent normalisation of possible imbalances in the intra-oral force equilibrium [3, 40], which is considered crucial for the presence or absence of open bite configurations, but is also discussed as a factor deteriorating Angle Class II/1 malocclusions. It may, therefore, be hypothesised that, with regard to the long-term stability of orthodontic treatment results achieved, orthodontic therapies may be more efficient if they are accompanied by additional training of the maintenance of physiological intra-oral pressure phases [40].

The biofunctional model may be used to define certain disturbances in different biofunctions and measure the functional status over time. In addition, therapeutic strategies can be discussed and compared with reference to their influence on oral compartments and valve mechanisms. For future evaluations, the model may be used to describe interaction, co-ordination, timing, force and pressure aspects of oral functions easily and in more detail, providing evidence-based data on the intra-oral postures of healthy subjects compared to patients after intra-oral tumour resection surgery, but also for a detailed evaluation of oral postures on the development of normal and malocclusion. An important aspect will also be the discussion base for interdisciplinary projects when describing biomechanical phenomena and their relationships to clinical research.

\section{Conclusions}

Given the study focus on intraluminal oral pressures, the following conclusions can be drawn:

1. Oral postural conditions can be differentiated on the basis of intra-oral pressure dynamics.

2. The formation of at least two functional compartments was confirmed. The sub-palatal space shows larger average negative pressure amplitudes than the inter-occlusal space.

3. Negative pressure values during swallowing and during the closed negative pressure condition have the same magnitude.

4. After deglutition, negative pressure plateaus can be passively maintained.

5. Closed resting posture after deglutition may explain previous observations of negative pressure in the palatal vault at rest.
6. Based on the proposed biofunctional oral model, intraoral pressure assessments may be a promising tool for interdisciplinary research, including malocclusion development, cleft palate research and oral rehabilitation after tumour surgery.

Conflict of interest The authors declare that they have no conflict of interest.

Open Access This article is distributed under the terms of the Creative Commons Attribution Noncommercial License which permits any noncommercial use, distribution, and reproduction in any medium, provided the original author(s) and source are credited.

\section{References}

1. Angle E (1907) Treatment of malocclusion of the teeth, 7th edn. White, Philadelphia

2. Abrams IN (1963) Oral muscle pressures. Angle Orthod 33 (33):83-104

3. Proffit W (1978) Equilibrium theory revisited: factors influencing position of the teeth. Angle Orthod 48:175-185

4. Mew JRC (2004) The postural basis of malocclusion: a philosophical overview. Am J Orthod Dentofacial Orthop 126:729-738

5. Kiliaridis S, Mejersjo C, Thilander B (1989) Muscle function and cranio-facial morphology: a clinical study in patients with myotonic dystrophy. Eur J Orthod 11:131-138

6. Gerato Pires M, Cantisani Di Francesco R, Seviovic Grumach A, Ferreira de Mello J (2005) Evaluation of inspiratory pressure in children with enlarged tonsils and adenoids. Braz J Otorhinolaryngol 71:598-601

7. Vig PS, Sarver DM, Hall DJ, Warren BN (1981) Quantitative evaluation of airflow in relation to facial morphology. Am J Orthod 79:272-273

8. Glatz-Noll E, Berg R (1991) Oral dysfunction in children with Down's syndrome: an evaluation of treatment effects by means of video registration. Eur J Orthod 13:446-451

9. Schopf PM (1972) Pressure load on incisor in dysfunction of mimic muscles. Fortschr Kieferorthop 33:187-203

10. Bresolin D, Shapiro GC, Shapiro PA, Dassel SW, Furuawa CT, Pierson WE et al (1984) Facial characteristics of children who breath through the mouth. Paediatrics 73:622-625

11. Lundeen HC, Gibbs CH (1982) Advances in occlusion. John Wright, Boston

12. Melsen B, Attina L, Suntueri M, Attina A (1987) Relationship between swallowing patterns, mode of respiration and developing malocclusion. Angle Orthod 57:113-119

13. Harvold EP, Chierier G, Vargervik K (1972) Experiments on the development of dental malocclusion. Am J Orthod 61:38-44

14. Tomes $C$ (1873) The bearing of the development of the jaws on irregularities. Dent Cosmos 15:292-296

15. Ballard CF (1966) The adaptive alveolar process. Ann R Coll Surg Engl 39:199-203

16. Breustedt A (1966) Die Funktion von Zunge, Lippen und Wangen im Lichte experimenteller Untersuchungen. J Orofac Orthop 27:327-337

17. Winders RV (1962) Recent findings in myometric research. Angle Orthod 32:38-43 
18. Kydd WL, Akamine JS, Mendel RA, Kraus BS (1963) Tongue and lip forces exerted during deglutition in subjects with and without anterior open bite. J Dent Res 42:858-866

19. Gould MSE Picton DCA (1975) Sub-atmospheric pressures and forces recorded from the labiobuccal surfaces of the teeth during swallowing in adult males. Br J Orthod 2:121-125

20. Ruan W, Chen M, Gu Z, Lu Y, Guo Q (2005) Muscular forces exerted on the normal deciduous dentition. Angle Orthod 75:785-790

21. Eckert-Möbius A (1953) Die Bedeutung der Zunge für die Nasenund Mundatmung. Fortschr Kieferorthop 14:229-239

22. Noltemeier H (1949) Einführung in die allgemeine Kiefer- und Gesichtsorthopädie. Alfeld, Hannover

23. Körbitz A (1914) Kursus der systematischen Orthodontik. Johann Ambrosius Barth, Leipzig

24. Fränkel R (1967) Die Dynamik des interokklusalen Unterdruckes. Deutsche Zahnärztliche Zeitschrift 22:282

25. Fröhlich K, Thüer U, Ingerwall B (1991) Pressure from the tongue on the teeth in young adults. Angle Orthod 61:17-24

26. Engelke W (2007) Systematische Rhonchopathiebehandlung in der zahnärztlichen Praxis. Cuvillier, Göttingen

27. Engelke W, Petersen C, Müller C (1995) Elektromagnetische Untersuchungen zur Physiologie oropharyngealer Schluckbewegungen. Sprache Stimme Gehör 19:105-113

28. Kieser J, Singh B, Swain M, Ichim I, Waddell JN, Kennedy D, Foster K, Livingstone V (2008) Measuring intraoral pressure: adaptation of a dental appliance allows measurement during function. Dysphagia 23:237-243

29. Lindner A, Hellsing E (1991) Cheek and lip pressure against maxillary dental arch during dummy sucking. Eur J Orthod 13:362-6

30. Brunner E, Domhof S, Langer F (2002) Nonparametric analysis of longitudinal data in factorial experiments. Wiley, New York
31. Lear CS, Morrees CFA (1969) Buccolingual muscle force and dental arch form. Am J Orthodont 56:379-393

32. Proffit WR, Norton LA (1970) The tongue and oral morphology: influence of tongue activity during speech and swallowing. Am Speech Hearing Ass Report 5:106-115

33. Thüer U, Sieber R, Ingervall B (1999) Cheek and tongue pressures in the molar areas and the atmospheric pressure in the palatal vault in young adults. Eur J Orthod 21:299-309

34. Walpole Day AJ, Foster TD (1970) The measurement of variations in intraoral air pressure. Angle Orthod 40:45-50

35. Shellhart WC, Moawad MI, Matheny J, Paterson RL, Hicks EP (1997) A prospective study of lip adaptation during six months of simulated mandibular expansion. Angle Orthod 67:47-54

36. Ono T, Hori K, Nokubi T (2004) Pattern of tongue pressure on hard palate during swallowing. Dysphagia 19:259-264

37. Engelke W, Hoch G, Bruns T, Striebeck M (1996) Simultaneous evaluation of articulatory velopharyngeal function under different dynamic conditions with EMA and videoendoscopy. Folia Phoniatr Logop 48(2):65-67

38. Schwartz AR, O'Donnell CP, Baron J, Schubert N, Alam D, Samadi SD, Smith PL (1998) The hypotonic upper airway in obstructive sleep apnea: role of structures and neuromuscular activity. Am J Respir Crit Care Med 157:1051-1057

39. Engelke W (2003) Ein Manöver zur Positionierung der Zunge am Gaumen. Sprache Stimme Gehör 27:171-175

40. Engelke W, Mendoza M, Repetto G (2006) Preliminary radiographic observations of the tongue repositioning manoeuvre. Eur J Orthod 28:618-23

41. Engelke W, Repetto G, Mendoza-Gärtner M, Knösel M (2007) Functional treatment of snoring using oral shields in conjunction with the tongue repositioning manoeuvre. Int J Odontostomatol 1:133-139 